\title{
Protective effect of myricetin in dextran sulphate sodium-induced murine ulcerative colitis
}

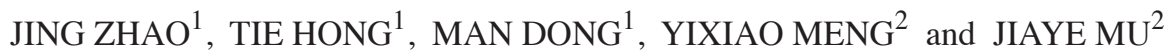 \\ ${ }^{1}$ Department of Pharmacology, School of Pharmacy, Jilin University, Changchun 130021; \\ ${ }^{2}$ College of Pharmacy, Yanbian University, Yanji 133002, P.R. China
}

Received September 9, 2012; Accepted November 16, 2012

DOI: $10.3892 / \mathrm{mmr} .2012 .1225$

\begin{abstract}
In the present study, the protective effect of myricetin administered orally at 200,100 or $50 \mathrm{mg} / \mathrm{kg}$ for 10 days was evaluated in a murine model of acute experimental colitis induced by dextran sulphate sodium (DSS). Macroscopic analysis was carried out to determine the effect of myricetin on pro-inflammatory cytokines, inflammatory markers and oxidative damage in biopsies of colonic tissues. The results showed that treatment with myricetin ameliorated body weight loss in a dose-dependent manner and significantly reduced histology scores. Myricetin decreased the production of nitric oxide (NO), myeloperoxidase (MPO) and malondialdehyde (MDA), while increasing the activity of superoxide dismutase (SOD) and glutathione peroxidase (GSH-Px). Furthermore, the levels of the cytokines interleukin-1 $\beta$ (IL-1 $\beta$ ) and interleukin-6 (IL-6) were significantly decreased. Taken together, the results suggest that the anticolitis effects of myricetin may be attributed to anti-inflammatory and antioxidant actions. Additional investigation is required to determine the detailed mechanisms of action.
\end{abstract}

\section{Introduction}

Inflammatory bowel diseases (IBDs), such as Crohn's disease (CD) and ulcerative colitis (UC), are chronic relapsing inflammatory disorders of the gastrointestinal tract (1). Although their precise aetiology is unknown, they are likely to be correlated with an abnormal exacerbated immune response to otherwise innocuous stimuli, which is not properly abrogated by the feedback system that normally downregulates the mucosal response to luminal factors (2). Similar to other inflammatory processes, IBD is characterised by an upregulation of the synthesis and release of a variety of pro-inflammatory

Correspondence to: Professor Tie Hong, Department of Pharmacology, School of Pharmacy, Jilin University, Fujin Road No. 1266, Jilin, Changchun 130021, P.R. China

E-mail: hongtie@jlu.edu.cn

Key words: myricetin, dextran sulphate sodium, ulcerative colitis, antioxidation, anti-inflammatory mediators, such as reactive oxygen species and cytokines, thus influencing mucosal integrity and leading to excessive tissue injury $(3,4)$. Currently, a specific causal treatment of IBD is not available, and the best regimen is the regulation of the oxidant/antioxidant balance.

Oral administration of dextran sulphate sodium (DSS) in mice induces colitis that resembles human UC (5). This model corresponds well to the clinical signs of human UC, thus may serve as a reliable model for studies on this disease. In this model, leukocytes, including neutrophils, lymphocytes and macrophages, have been reported to infiltrate inflamed tissues (6). Simultaneously, there are numerous reactive oxygen species in the colonic mucosa. Oxidative stress, with its dual effect of free radical generation and enhanced lipid peroxidation, is the mainstay of disease evolution (7). The production and release of reactive oxygen species by immune cells appear to play a crucial role in the pathophsyiology of UC (8).

Flavonoids have been suggested to exert human health benefits, which may be mediated by their antioxidant and anti-inflammatory activities. Among the known flavonoids, myricetin $\left(3,3^{\prime}, 4^{\prime}, 5,5^{\prime}, 7\right.$-hexahydroxyflavone) is one of the major flavonoids found in several foods, including onions, berries, grapes and red wine (9). Myricetin has several beneficial effects, including anti-inflammatory (10), antioxidant (11), analgesic and anticarcinogenic effects $(12,13)$. These pleiotropic effects render myricetin a suitable candidate for study. The main objective of the present study was to evaluate the anticolitis effects and possible mechanisms of action of myricetin in a model of DSS-induced colitis.

\section{Materials and methods}

Reagents. Myricetin was purchased from Sigma-Aldrich (St. Louis, MO, USA) and DSS was purchased from Wako Pure Chemical Industries Inc. (Tokyo, Japan).

Animals. Forty specific pathogen-free female BALB/c mice were housed in standard cages with wood shavings. Eight animals/cage were maintained in a room with a carefully controlled ambient temperature $\left(25^{\circ} \mathrm{C}\right)$ and artificial illumination (12 h of light from 8:00 a.m. to 8:00 p.m.). The experiments were approved by the ethics committee of Jilin University Changchun, China. 
Table I. Degree of inflammation in microscopic cross-sections of the colon.

\begin{tabular}{lllll}
\hline No. & Ulceration & \multicolumn{1}{c}{ Epithelium } & \multicolumn{1}{c}{ Infiltration } & \multicolumn{1}{c}{ Lymphoid follicles } \\
\hline 0 & No ulcers & Normal morphology & No infiltrate & No lymphoid follicles \\
1 & 1 ulcer & Loss of goblet cells & Infiltrate around crypt bases & 1 lymphoid follicle \\
2 & 2 ulcers & Loss of goblet cells in large areas & Infiltrate reaching to muscularis mucosae & 2 lymphoid follicles \\
3 & 3 ulcers & Loss of crypts & Extensive infiltration reaching the muscularis & 3 lymphoid follicles \\
4 & $>3$ ulcers & Loss of crypts in large areas & Infiltration of the submucosa & $>3$ lymphoid follicles \\
\hline
\end{tabular}

Induction of colitis. Mice were given drinking water containing 5\% (wt/vol) DSS (mol wt 5,000 dissolved in drinking water) ad libitum for 10 days. The normal group was given water only. Previous results have shown that there is acute inflammation at this stage, as indicated by the increased number of polymorphonuclear leukocytes, multiple erosive lesions and the loss of crypts (14).

Treatment with myricetin. The mice were treated with myricetin at 200, 100 or $50 \mathrm{mg} / \mathrm{kg}$ body weight daily, beginning on the day on which oral DSS water was given. The normal group was administered an equal volume of water orally.

Morphological analysis. At the end of the experiment, the body weight and haemoglobin content were measured. After measuring the colonic length, colon samples were fixed in $10 \%$ formalin solution $(\mathrm{pH} 7.2)$.

Grading of histological changes. Colon samples were embedded in paraffin. Serial sections $4 \mu \mathrm{m}$ thick were prepared and stained with haematoxylin and eosin $(H \& E)$ for histological grading and evaluation. The degree of inflammation in microscopic cross-sections of the colon was evaluated as shown in Table I.

Assessment of myeloperoxidase (MPO) activity in colonic tissue. MPO activity was determined by a modified method described by Suzuki et al (15). In brief, colonic tissue was weighed and homogenised with a homogeniser for $40 \mathrm{sec}$ in ice-cold $50 \mathrm{mmol} / \mathrm{l}$ phosphate-buffered saline (PBS; pH 6.0) containing $0.5 \%$ hexadecyl-trimethylammonium bromide. The homogenate was thawed three times, followed by repeated sonication for $30 \mathrm{sec}$ each time. The final MPO activity was represented as $\mathrm{U} / \mathrm{mg}$ tissue.

Assessment of superoxide dismutase (SOD) and glutathione peroxidase (GSH-Px) activity and malondialdehyde (MDA) content in colonic tissue. After thawing, colon samples were weighed and homogenised in $0.3 \mathrm{ml} \mathrm{PBS} \mathrm{(pH} \mathrm{7.2)} \mathrm{at} 4^{\circ} \mathrm{C}$. The protein concentration was determined quantitatively using the BAC 100 Protein Determination kit (Shanghai Bio-Technology Co., Ltd., Shanghai, China). GSH-Px activity and the MDA content in colonic tissue were measured by chemical chromatometry using related assay kits (Jiancheng Biotech, Nanjing, China). The final value of GSH-Px is presented as $\mathrm{U} / \mathrm{mg}$ protein, and MDA is presented as $\mathrm{nmol} / \mathrm{mg}$ protein. The SOD activity in colonic tissue was measured using the method of Ohkawa et al (16) to evaluate the ability of the xanthinexanthine oxidase system to inhibit the oxidation of oxymine. $\mathrm{SOD}$ is presented as $\mathrm{U} / \mathrm{mg}$ protein.

Assessment of colonic nitric oxide (NO) content. NO content was determined by measuring its stable metabolites, nitrite $\left(\mathrm{NO}_{2}^{-}\right)$and nitrate $\left(\mathrm{NO}_{3}^{-}\right)$, based on the method described by Miranda et al (17). In brief, $0.1 \mathrm{ml}$ of colonic homogenate $(20 \%)$ was added to $0.1 \mathrm{ml}$ of methylalcohol and centrifuged at $12,000 \mathrm{x} \mathrm{g}$ for $10 \mathrm{~min}$. An aliquot of the resultant supernatant $(0.1 \mathrm{ml})$ was aspirated and mixed with $0.1 \mathrm{ml}$ of vanadium (III) chloride. Then, $50 \mu \mathrm{l}$ of sulphanilamide solution and $50 \mu 1$ of $N$-(1-naphthyl)ethylenediamine dihydrochloride (NEDD) were added and incubated at $37^{\circ} \mathrm{C}$ for $30 \mathrm{~min}$. The optical density was measured at $540 \mathrm{~nm}$ against a blank using the spectrophotometer UVWin 5.

Assessment of interleukin (IL)-1 $\beta$ and IL-6. Colon samples were weighed and homogenised in $0.3 \mathrm{ml}$ PBS ( $\mathrm{pH} 7.2$ ) containing $1 \%$ bovine serum albumin (BSA) at $4^{\circ} \mathrm{C}$. The homogenate was thawed three times and centrifuged at $12,000 \mathrm{x}$ g for $10 \mathrm{~min}$. Cytokine levels were assayed twice with quantitative IL-1 $\beta$ and IL-6 enzyme-linked immunosorbent assay (ELISA) kits (eBioscience, Inc., San Diego, CA, USA). IL-1 $\beta$ and IL-6 values are expressed as $\mathrm{pg} / \mathrm{mg}$ tissues.

Statistical analyses. The data are expressed as the mean \pm SEM. The statistical significance of the difference in each parameter among the groups was evaluated using a one-way analysis of variance (ANOVA) followed by the Fisher's protected least significant difference (PLSD) comparison tests for post hoc t-tests. $\mathrm{P}<0.05$ was considered to indicate a statistically significant difference. Scores were analysed using the Wilcoxon's test.

\section{Results}

Effects on the general condition of mice with colitis. We found that BALB/c mice subjected to the oral administration of $5 \%$ DSS regularly developed pancolitis with severe diarrhoea and rectal prolapse accompanied by extensive wasting disease. In severe cases, gross blood adhering to the anus was noted. Beginning on the 4th day subsequent to DSS administration, the body weight began to decrease, and remained significantly decreased compared with normal mice until the 10th day. However, the administration of myricetin significantly reversed the loss of body weight (Fig. 1). 
Table II. Effect of myricetin on damage score and blood haemoglobin.

\begin{tabular}{lcc}
\hline Group & Damage score & $\begin{array}{c}\text { Blood haemoglobin } \\
(\mathrm{g} / \mathrm{dl})\end{array}$ \\
\hline Normal & 0 & $12.12 \pm 0.87$ \\
DSS-induced colitis & $11(13-9)^{\mathrm{d}}$ & $9.04 \pm 0.61^{\mathrm{d}}$ \\
Myricetin (mg/kg) & & \\
200 & $6(8-4)^{\mathrm{b}}$ & $10.01 \pm 0.26^{\mathrm{c}}$ \\
100 & $8(10-7)^{\mathrm{a}}$ & $9.88 \pm 0.32^{\mathrm{b}}$ \\
50 & $10(13-8)$ & $9.40 \pm 0.15^{\mathrm{b}}$ \\
\hline
\end{tabular}

Damage score is expressed as median (range). Blood haemoglobin is expressed as the mean $\pm \mathrm{SEM} ; \mathrm{n}=8$. ${ }^{\mathrm{a}} \mathrm{P}<0.05,{ }^{\mathrm{b}} \mathrm{P}<0.01,{ }^{\mathrm{c}} \mathrm{P}<0.001$ vs. the DSS model. ${ }^{\mathrm{d}} \mathrm{P}<0.001$ vs. the normal group. DSS, dextran sulphate sodium.

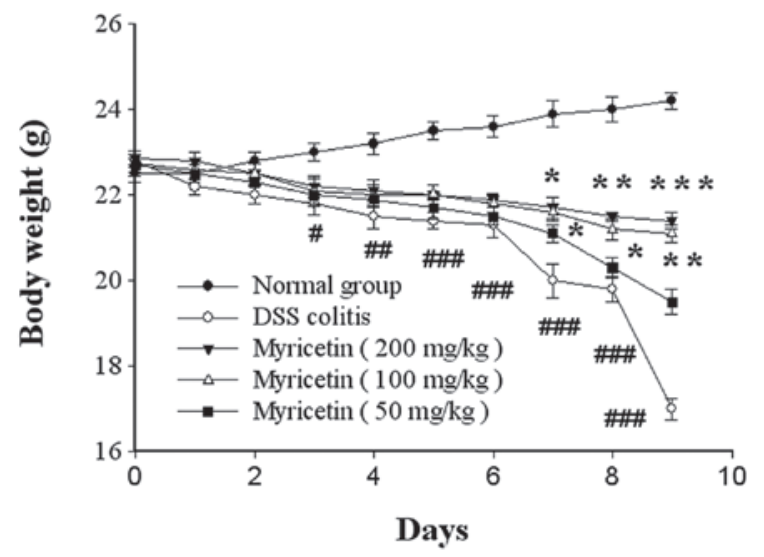

Figure 1. Effect of myricetin administration on the time-course changes in the mouse body weight. ${ }^{*} \mathrm{P}<0.05,{ }^{* *} \mathrm{P}<0.01$ vs. the DSS model; ${ }^{*} \mathrm{P}<0.05$, ${ }^{\# \#} \mathrm{P}<0.01,{ }^{\# \# "} \mathrm{P}<0.001$ vs. normal. Data are presented as the mean $\pm \mathrm{SEM} ; \mathrm{n}=8$. DSS, dextran sulphate sodium.

Effect on damage score and histological evaluation. The severity of UC-like lesions was most marked in the colon on the 10th day. Compared with normal mice, the distal colon of DSS-treated mice showed intense inflammatory cellular infiltration in all the layers, with polymorphonuclear leukocytes and multiple erosions. Crypt abscesses and regenerating epithelium were observed in the colonic mucosa. Myricetin treatment attenuated morphological damage but showed mild cellular infiltration (Table II, Fig. 2).

Compared with the DSS-induced colitis groups, the damage score and the content of blood haemoglobin in the myricetin groups were significantly lower. Mice treated with 200 and $100 \mathrm{mg} / \mathrm{kg}$ myricetin showed a significantly lower damage score and blood haemoglobin content $(\mathrm{P}<0.01$ and $\mathrm{P}<0.05$, respectively), although those treated with $50 \mathrm{mg} / \mathrm{kg}$ showed no significant differences. The results showed a concentrationresponse correlation (Table II).

Effect on the length of the colon. The colon and caecum of the DSS-treated mice were significantly shorter compared with those of the normal group. The administration of myric-
A

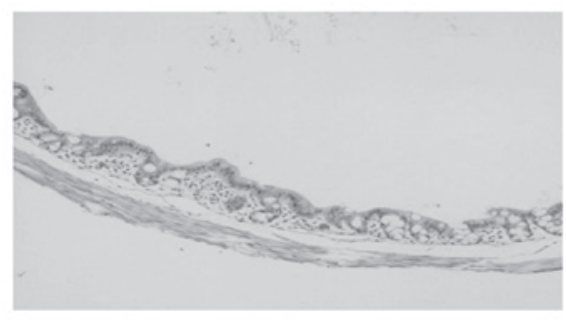

B

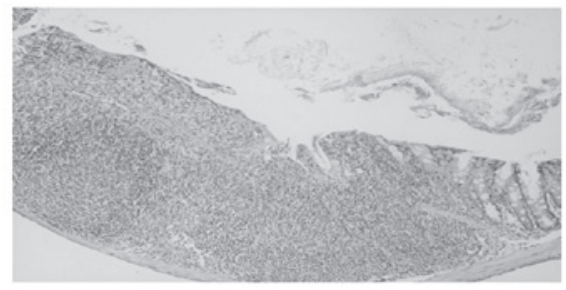

C

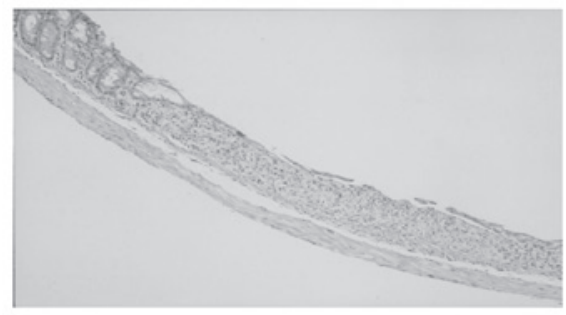

D

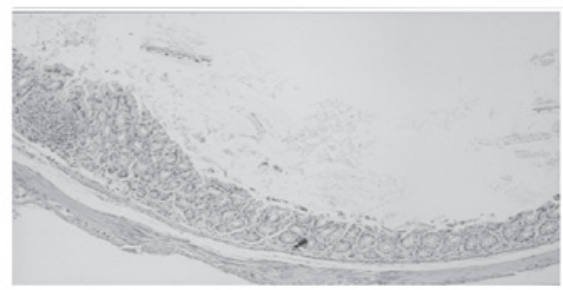

$\mathbf{E}$

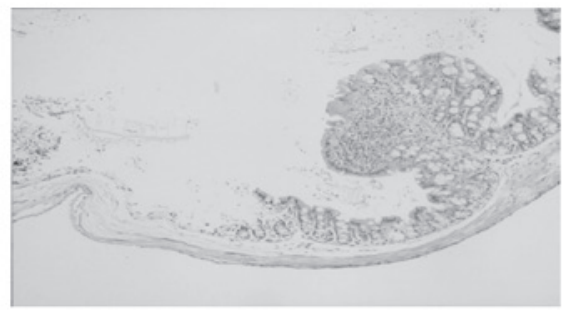

Figure 2. Effect of myricetin on histological changes of the colon [haematoxylin and eosin (H\&E) staining; magnification, x100]. (A) Normal group; (B) DSS colitis; (C) Myricetin (200 mg/kg); (D) Myricetin (100 mg/kg) and (E) Myricetin $(50 \mathrm{mg} / \mathrm{kg})$. DSS, dextran sulphate sodium.

etin significantly increased the length of the shortened colon induced by DSS (Fig. 3).

Effect on MPO, GSH-Px and SOD activity, and MDA and NO content in colonic tissue. The MPO levels were $0.106 \pm 0.012 \mathrm{U} / \mathrm{mg}$ colonic tissue in normal mice and $0.260 \pm 0.018 \mathrm{U} / \mathrm{mg}$ colonic tissue in mice with DSS-induced colitis. Myricetin at 50, 100 and $200 \mathrm{mg} / \mathrm{kg}$ decreased the MPO levels to $0.180 \pm 0.013,0.166 \pm 0.01$ and $0.159 \pm 0.018 \mathrm{U} / \mathrm{mg}$ colonic tissue, respectively (Fig. 4).

The GSH-Px activity was $39.0 \pm 6.0 \mathrm{U} / \mathrm{mg}$ colonic tissue in normal mice and $29.0 \pm 5.0 \mathrm{U} / \mathrm{mg}$ colonic tissue in mice with DSS-induced colitis. Myricetin at doses of 50, 100 and $200 \mathrm{mg} / \mathrm{kg}$ increased the GSH-Px activity to $30.1 \pm 3.1,35.0 \pm 4.2$ and $40.1 \pm 6.3 \mathrm{U} / \mathrm{mg}$ colonic tissue, respectively (Fig. 5). 


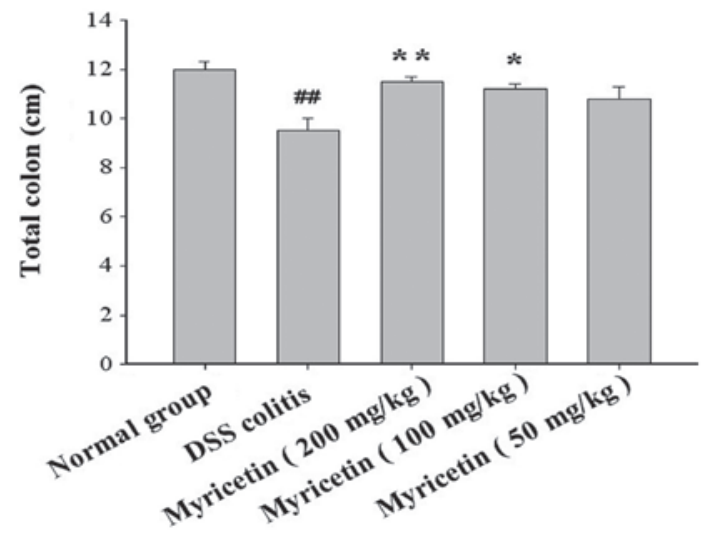

Figure 3. Effect of the administration of myricetin on colonic length. ${ }^{*} \mathrm{P}<0.05$, ${ }^{* *} \mathrm{P}<0.01$ vs. the DSS model; ${ }^{\# /} \mathrm{P}<0.01$ vs. normal. Data are presented as the mean \pm SEM; $n=8$. DSS, dextran sulphate sodium.

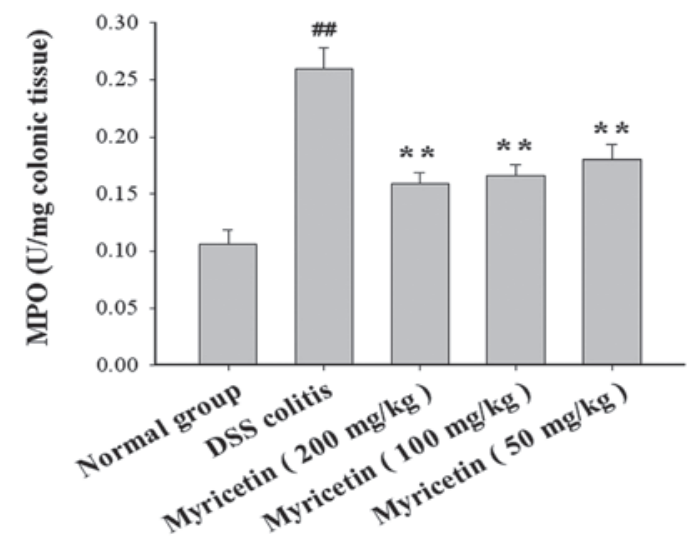

Figure 4. Effect of myricetin administration on MPO levels in colonic tissue. ${ }^{* *} \mathrm{P}<0.01$ vs. the DSS model; ${ }^{\# \# \#} \mathrm{P}<0.001$ vs. normal. Data are presented as the mean \pm SEM; $n=8$. MPO, myeloperoxidase; DSS, dextran sulphate sodium.

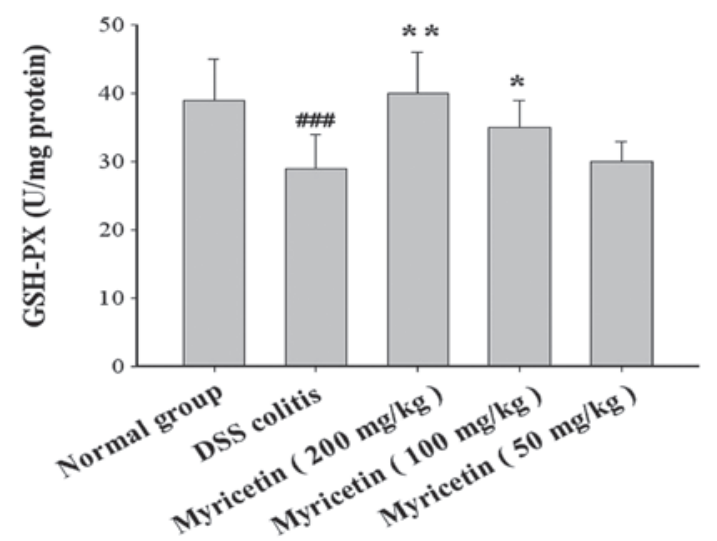

Figure 5. Effect of myricetin administration on GSH-Px activity in colonic tissue. ${ }^{*} \mathrm{P}<0.05,{ }^{* *} \mathrm{P}<0.01$ vs. the DSS model; ${ }^{\# \#} \mathrm{P}<0.001$ vs. normal.Data are presented as the mean \pm SEM; $n=8$. GSH-Px, glutathione peroxidase; DSS, dextran sulphate sodium.

The SOD activity was $81.0 \pm 6.4 \mathrm{U} / \mathrm{mg}$ colonic tissue in normal mice and $41.1 \pm 5.6 \mathrm{U} / \mathrm{mg}$ colonic tissue in mice with DSS-induced colitis. Myricetin at 50, 100 and $200 \mathrm{mg} / \mathrm{kg}$ increased the SOD activity to $48.1 \pm 4.2,56.2 \pm 3.4$ and $66.4 \pm 5.6 \mathrm{U} / \mathrm{mg}$ colonic tissue, respectively (Fig. 6).

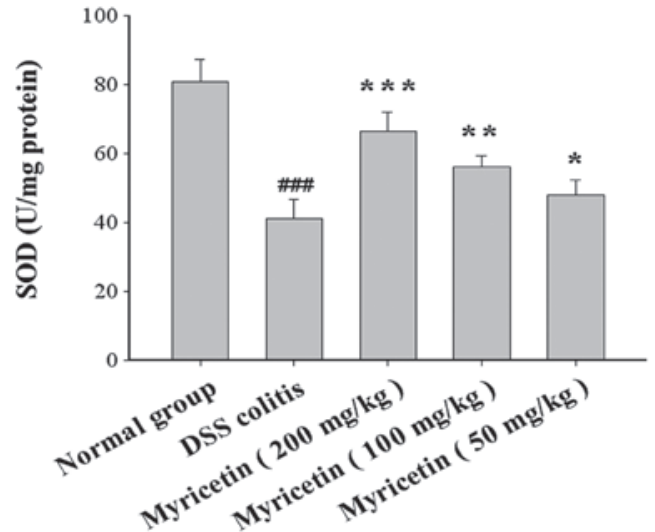

Figure 6. Effect of myricetin administration on SOD activity in colonic tissue. ${ }^{*} \mathrm{P}<0.05,{ }^{* * *} \mathrm{P}<0.01,{ }^{* * * *} \mathrm{P}<0.001$ vs. the DSS model; ${ }^{\# \# \# "} \mathrm{P}<0.001$ vs. normal. Data are presented as the mean \pm SEM; $n=8$. SOD, superoxide dismutase; DSS, dextran sulphate sodium.

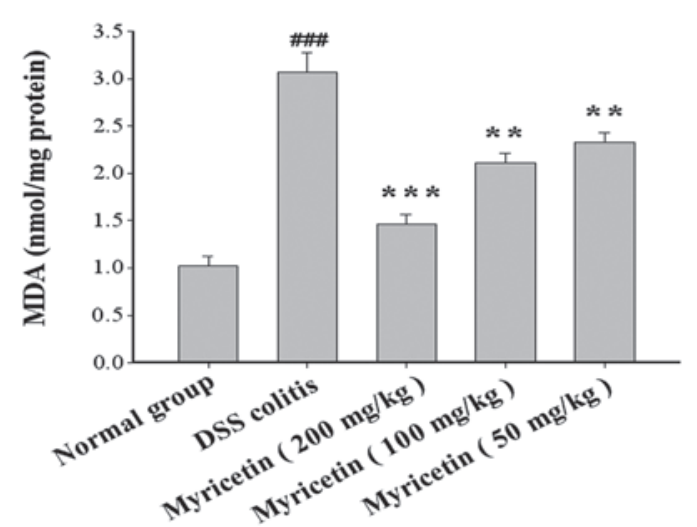

Figure 7. Effect of myricetin administration on MDA content in colonic tissue. ${ }^{* *} \mathrm{P}<0.01,{ }^{* * *} \mathrm{P}<0.001$ vs. the DSS model; ${ }^{\# \# "} \mathrm{P}<0.001$ vs. normal.Data are presented as the mean \pm SEM; $n=8$. MDA, malondialdehyde; DSS, dextran sulphate sodium.

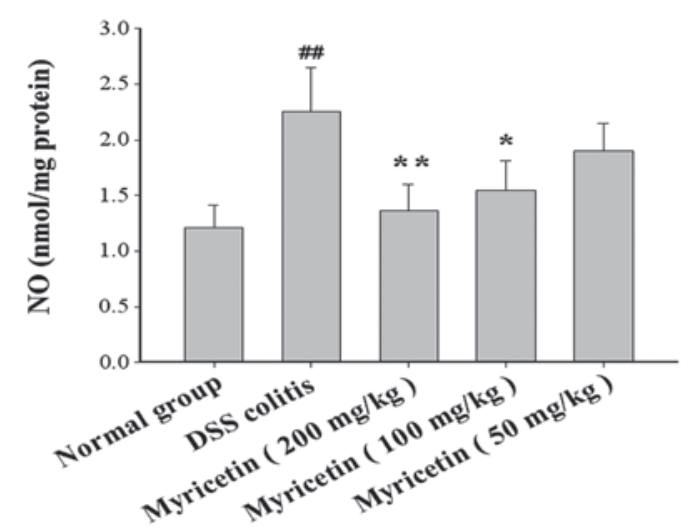

Figure 8 Effect of myricetin administration on $\mathrm{NO}$ content in colonic tissue ${ }^{*} \mathrm{P}<0.05,{ }^{* * *} \mathrm{P}<0.01$ vs. the DSS model; ${ }^{\# \prime \prime} \mathrm{P}<0.05$ vs. normal. Data are presented as the mean \pm SEM; $n=8$. NO, nitric oxide; DSS, dextran sulphate sodium.

The MDA content was $1.02 \pm 0.10 \mathrm{nmol} / \mathrm{mg}$ protein in normal mice and $3.07 \pm 0.20 \mathrm{nmol} / \mathrm{mg}$ protein in mice with DSS-induced colitis. Myricetin at 50, 100 and $200 \mathrm{mg} / \mathrm{kg}$ decreased the MDA content to $2.33 \pm 0.10,2.11 \pm 0.11$ and $1.46 \pm 0.11 \mathrm{nmol} / \mathrm{mg}$ protein, respectively (Fig. 7). 


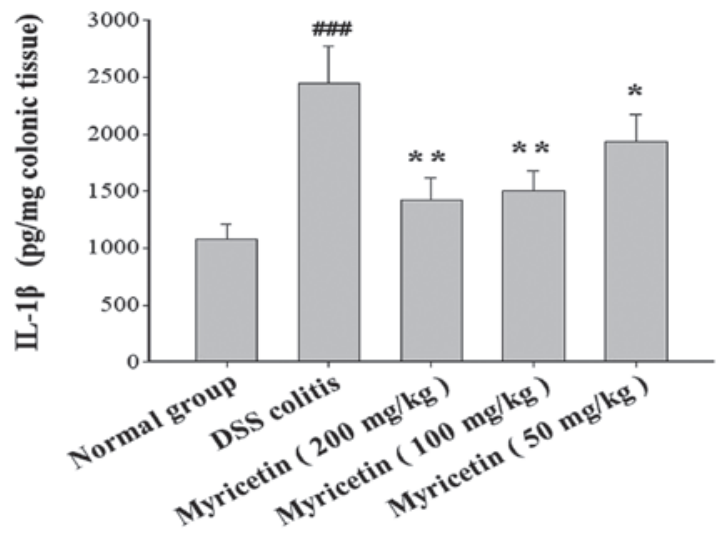

Figure 9. Effect of myricetin administration on IL-1 $\beta$ concentration in colonic tissue. ${ }^{*} \mathrm{P}<0.05,{ }^{* *} \mathrm{P}<0.01$ vs. the DSS model; ${ }^{\# \# \#} \mathrm{P}<0.001$ vs. normal. Data are presented as the mean \pm SEM; $n=8$. IL- $1 \beta$, interleukin-1 $\beta$; DSS, dextran sulphate sodium.

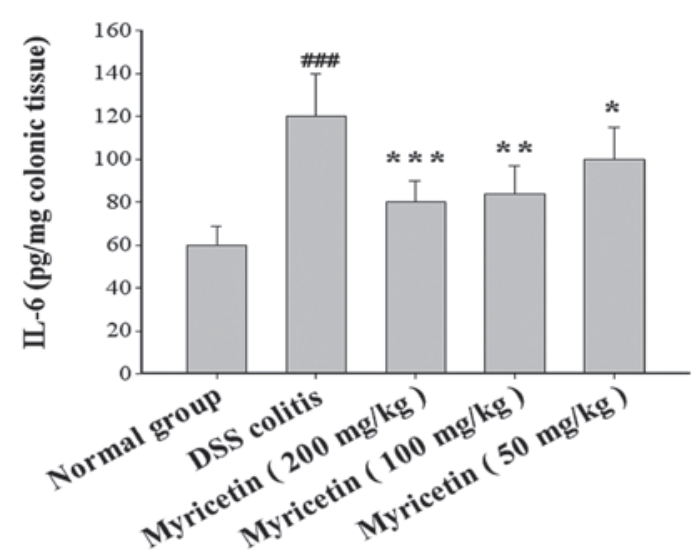

Figure 10. Effect of myricetin administration on IL- 6 concentration in colonic tissue. ${ }^{*} \mathrm{P}<0.05,{ }^{* *} \mathrm{P}<0.01,{ }^{* * *} \mathrm{P}<0.001$ vs. the DSS model; ${ }^{\# \# /} \mathrm{P}<0.001$ vs. normal. Data are presented as the mean \pm SEM; $n=8$. IL-6, interleukin-6; DSS, dextran sulphate sodium.

The NO content was $1.21 \pm 0.20 \mu \mathrm{mol} / \mathrm{mg}$ protein in normal mice and $2.25 \pm 0.40 \mu \mathrm{mol} / \mathrm{mg}$ protein in mice with DSS-induced colitis. Myricetin at 50, 100 and $200 \mathrm{mg} / \mathrm{kg}$ decreased the NO content to $1.90 \pm 0.25,1.55 \pm 0.26$ and $1.36 \pm 0.24 \mu \mathrm{mol} / \mathrm{mg}$ protein, respectively (Fig. 8).

Effect on IL-1 $\beta$ and IL- 6 in colonic tissue. DSS-induced colitis was accompanied by a disturbance in cytokine levels. The effects of myricetin on IL- $1 \beta$ and IL- 6 production in colonic tissue were evaluated. The administration of myricetin to the DSS-induced colitis group resulted in lower levels of IL-1 $\beta$ and IL-6 (Figs. 9 and 10).

\section{Discussion}

In this study, the oral administration of myricetin for 10 days markedly prevented the loss of body weight and reduced the damage score in the colonic mucosa of DSS-induced colitis, and histological analysis demonstrated that myricetin ameliorated the pathological manifestations of DSS colitis, including inflammatory cell infiltration, crypt abscesses and regenerating epithelium, in the colonic mucosa. Mucosal lesions in UC are characterised by a dense inflammatory cell infiltrate that primarily contains neutrophils, macrophages and lymphocytes. During chronic inflammation, whereby the sustained production of reactive oxygen species (ROS) occurs, antioxidant defences may weaken, resulting in oxidative stress. Increased ROS levels in the intestinal epithelial cell membrane may lead to oxidative damage mediated by free radical attacks and lipid peroxidation, which may be an early critical event in the model of experimental IBD. Acute attacks of UC lead to an inflamed colonic mucosa, which contributes to an excess production of reactive oxygen metabolites by lipid peroxidation (18). Inflammatory tissue injury may further stimulate ROS production and reactive oxygen metabolites, thus forming a positive feedback loop and rendering the antioxidant system insufficient (19). DSS-induced colitis is a well-established experimental model with several of the signs and symptoms of human UC. ROS are highly reactive, and their levels are significantly increased in the colonic mucosa (20).

Myricetin treatment was found to significantly lower MPO activity, MDA and NO content and increase the activity of SOD and GSH-Px. MPO and NO are known sources of free radicals and are able to induce the reduction of ferritin $\left(\mathrm{Fe}^{3+}\right)$ to free $\mathrm{Fe}^{2+}$, contributing to oxidative damage $(21,22)$. Moreover, increased MDA activity leads to lipid peroxidation, which causes the cross-linking of protein and nucleic acid molecules and cell toxicity. MDA is an essential co-factor of GSH-Px and SOD and plays a significant antioxidative role by binding to the active site of GSH-Px. SOD protects cells against ROS-induced damage by removing these molecules. GSH-Px detoxifies organic peroxides and $\mathrm{H}_{2} \mathrm{O}_{2}$ and permits the regeneration of cellular lipid molecules through reacylation in the cell membrane.

Furthermore, our data showed that myricetin was able to decrease the production of IL- $1 \beta$ and IL- 6 . Inhibiting the action of endogenous IL-1 $\beta$ or IL- 6 attenuates acute and chronic experimental colitis and their systemic complications (23-25). Previous studies have shown that the anti-inflammatory mechanisms of myricetin are most likely associated with the inhibition of antioxidant activity (26). Therefore, myricetin may exert its effects in DSS colitis through its antioxidant effect.

In conclusion, myricetin may ameliorate inflammation in mice treated with DSS. The mechanism is likely due to its antioxidant effect. Myricetin may be used as a novel therapeutic agent of colitis.

\section{References}

1. Xavier RJ and Podolsky DK: Unravelling the pathogenesis of inflammatory bowel disease. Nature 448: 427-434, 2007.

2. Torres MI and Rios A: Current view of the immunopathogenesis in inflammatory bowel disease and its implications for therapy. World J Gastroenterol 14: 1972-1980, 2008.

3. Carroll IM, Andrus JM, Bruno-Bárcena JM, Klaenhammer TR, Hassan HM and Threadgill DS: Anti-inflammatory properties of Lactobacillus gasseri expressing manganese superoxide dismutase using the interleukin 10-deficient mouse model of colitis. Am J Physiol Gastrointest Liver Physiol 293: G729-G738, 2007.

4. Dutra RC, Claudino RF, Bento AF, Marcon R, Schmidt EC, Bouzon ZL, Pianowski LF and Calixto JB: Preventive and therapeutic euphol treatment attenuates experimental colitis in mice. PLoS One 6: e27122, 2011. 
5. Okayasu I, Hatakeyama S, Yamada M, Ohkusa T, Inagaki Y and Nakaya R: A novel method in the induction of reliable experimental acute and chronic ulcerative colitis in mice. Gastroenterology 98: 694-702, 1990.

6. Tokoi S, Ohkusa T, Okayasu I and Nakamura K: Population changes in immunoglobulin-containing mononuclear cells in dextran sulfate sodium-induced coltitis. J Gastroenterol 31: 182-188, 1996.

7. Rezaie A, Parker RD and Abdollahi M: Oxidative stress and pathogenesis of inflammatory bowel disease: an epiphenomenon or the cause? Dig Dis Sci 52: 2015-2021, 2007.

8. Damiani CR, Benetton CA, Stoffel C, Bardini KC, Cardoso VH, Di Giunta G, Pinho RA, Dal-Pizzol F and Streck EL: Oxidative stress and metabolism in animal model of colitis induced by dextran sulfate sodium. J Gastroenterol Hepatol 22: 1846-1851, 2007.

9. Castillo-Muñoz N, Gómez-Alonso S, García-Romero E and Hermosín-Gutiérrez I: Flavonol profiles of Vitis vinifera red grapes and their single-cultivar wines. J Agric Food Chem 55: 992-1002, 2007.

10. Lee YS and Choi EM: Myricetin inhibits IL-1beta-induced inflammatory mediators in SW982 human synovial sarcoma cells. Int Immunopharmacol 10: 812-814, 2010.

11. Chen W, Li Y, Li J, Han Q, Ye L and Li A: Myricetin affords protection against peroxynitrite-mediated DNA damage and hydroxyl radical formation. Food Chem Toxicol 49: 2439-2444, 2011.

12. Nirmala P and Ramanathan M: Effect of myricetin on 1,2 dimethylhydrazine induced rat colon carcinogenesis. J Exp Ther Oncol 9: 101-108, 2011.

13. Kang NJ, Jung SK, Lee KW and Lee HJ: Myricetin is a potent chemopreventive phytochemical in skin carcinogenesis. Ann NY Acad Sci 1229: 124-132, 2011.

14. Okayasu I, Hatakeyama S, Yamada M, Ohkusa T, Inagaki Y, and Nakaya R: A novel method in the induction of reliable experimental acute and chronic ulcerative colitis in mice. Gastroenterology 98: 694-702, 1990.

15. Suzuki K, Ota H, Sasagawa S, Sakatani T and Fujikura T: Assay method for myeloperoxidase in human polymorphonuclear leukocytes. Anal Biochem 132: 345-352, 1983.
16. Ohkawa $\mathrm{H}$, Ohishi $\mathrm{N}$ and Yagi K: Assay for lipid peroxides in animal tissues by thiobarbituric acid reaction. Anal Biochem 95: 351-358, 1979.

17. Miranda KM, Espey MG and Wink DA: A rapid, simple spectrophotometric method for simultaneous detection of nitrate and nitrite. Nitric Oxide 5: 62-71, 2001

18. Keshavarzian A, Morgan G, Sedghi S, Gordon JH and Doria M: Role of reactive oxygen metabolites in experimental colitis. Gut 31: 786-790, 1990

19. Seril DN, Liao J, Yang GY and Yang CS: Oxidative stress and ulcerative colitis-associated carcinogenesis: studies in humans and animal models. Carcinogenesis 24: 353-362, 2003.

20. Ishihara T, Tanaka K, Tasaka Y, Namba T, Suzuki J, Ishihara T, Okamoto S, Hibi T, Takenaga M, Igarashi R, Sato K, Mizushima Y and Mizushima T: Therapeutic effect of lecithinized superoxide dismutase against colitis. J Pharmacol Exp Ther 328: 152-164, 2009.

21. Sutton A, Imbert A, Igoudjil A, Descatoire V, Cazanave S, Pessayre D and Degoul F: The manganese superoxide dismutase Ala16Val dimorphism modulates both mitochondrial import and mRNA stability. Pharmacogenet Genomics 15: 311-319, 2005.

22. Creveling CR: The role of catechol-O-methyltransferase in the inactivation of catecholestrogen. Cell Mol Neurobiol 23: 289-291, 2003.

23. Rogler G and Andus T: Cytokines in inflammatory bowel disease. World J Surg 22: 382-389, 1998.

24. Arai Y, Takanashi H, Kitagawa H and Okayasu I: Involvement of interleukin-1 in the development of ulcerative colitis induced by dextran sulfate sodium in mice. Cytokine 10: 890-896, 1998.

25. Naito Y, Takagi T, Uchiyama K, Kuroda M, Kokura S, Ichikawa H, Yanagisawa R, Inoue K, Takano H, Satoh M, Yoshida N, Okanoue $\mathrm{T}$ and Yoshikawa T: Reduced intestinal inflammation induced by dextran sodium sulfate in interleukin-6-deficient mice. Int J Mol Med 14: 191-196, 2004.

26. Wang SJ, Tong Y, Lu S, Yang R, Liao X, Xu YF and Li X: Antiinflammatory activity of myricetin isolated from Myrica rubra Sieb. et Zucc. leaves. Planta Med 76: 1492-1496, 2010. 